\title{
Correction to: Super selective intra-arterial cerebral infusion of modern chemotherapeutics after blood-brain barrier disruption: where are we now, and where we are going
}

Randy S. D'Amico ${ }^{1}$ (D) Deepak Khatri ${ }^{1} \cdot$ Noah Reichman $^{1} \cdot$ Nitesh V. Patel ${ }^{1} \cdot$ Tamika Wong $^{1} \cdot$ Sherese R. Fralin $^{1}$. Mona $\mathrm{Li}^{1}$ - Jason A. Ellis ${ }^{1}$. Rafael Ortiz ${ }^{1}$. David J. Langer ${ }^{1}$. John A. Boockvar ${ }^{1}$

Published online: 13 March 2020

(c) Springer Science+Business Media, LLC, part of Springer Nature 2020

Correction to: Journal of Neuro-Oncology https://doi.org/10.1007/s11060-020-03435-6

The name of author Jason A. Ellis was missing in the intial online publication, and there was a typo in the sixth author's first name. The original article has been corrected.

Publisher's Note Springer Nature remains neutral with regard to jurisdictional claims in published maps and institutional affiliations.

The original article can be found online at https://doi.org/10.1007/ s11060-020-03435-6.

Randy S. D’Amico

rdamico8@northwell.edu

1 Department of Neurosurgery, Zucker School of Medicine At

Hofstra/ Northwell Lenox Hill Brain Tumor Center, Lenox

Hill Hospital, Northwell Health, New York, NY, USA 